\title{
Reading treatment helps children with dyslexia and changes activity in language areas of the brain
}

\author{
Shalini Narayana, PhD; and Jinhu Xiong, PhD
}

\section{What Is Brain Activation?}

Brain activation is what happens when different parts of the brain are doing work, or are active. When a part of the brain is active, it uses more oxygen. This can be studied using a brain imaging test called fMRI. When someone is reading, there is more activity in the language area of the brain. The figure shows a $\mathrm{fMRI}$ of a normal person reading. The arrows point to parts of the brain that are activated. Changes in brain activation patterns after treatment can also be studied using fMRI. This method is an important tool to study children because it is non-invasive (does not require injections and has no serious side effects).

\section{Why Use fMRI to Study Children with Dyslexia?}

Dyslexia is a learning disability that affects a person's ability to read. Dys-

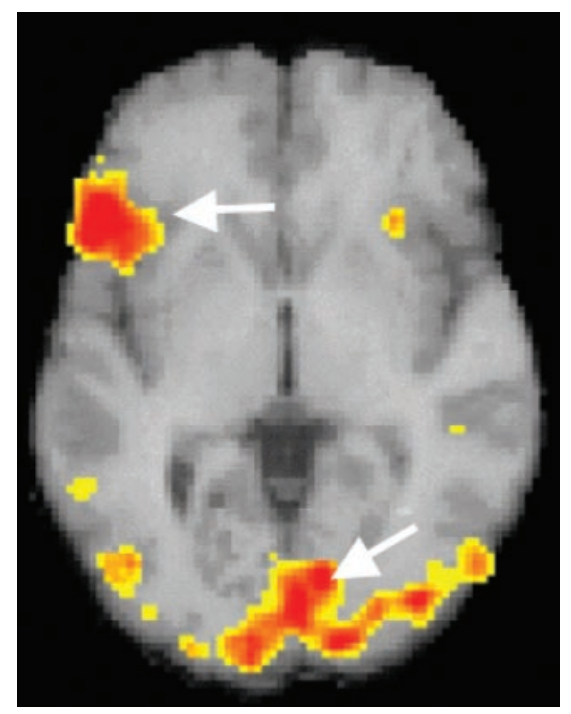

Figure. fMRI image of a normal person reading. The arrow points to the part of the brain that is activated. lexia is the most common learning disability in the U.S., affecting about $20 \%$ of Americans. We have just started understanding the specific problems in the brain that lead to dyslexia. People with dyslexia have different levels of brain activity and connections in the language area than people without dyslexia. Scientists believe that this leads to the problems with reading and spelling that dyslexic people have.

In this issue of Neurology, Aylward and her colleagues examine the effects of reading treatment on brain activation in children with dyslexia. This study examined the differences in brain activity using fMRI in children with and without dyslexia while the children performed the same two language tasks. The dyslexic children received comprehensive reading treatment. Changes in brain activity after this treatment in dyslexic children were compared with brain activity in children without dyslexia.

\section{Who Was in the Study?}

The study included 10 children (4 girls and 6 boys) with dyslexia and 11 normal readers ( 5 girls and 6 boys). Children in both groups were between 11 and 12 years of age. All children underwent fMRI scanning. Children with dyslexia received 28 hours (2 hours/ day $\times 14$ days) of reading treatment. At the end of the treatment these children underwent a second scan. The normal readers received no treatment. They received a second scan about 3 months later.

\section{How Were Language Skills Tested Using the fMRI?}

The fMRI scans were performed with two language tasks called phoneme mapping and morpheme mapping. Phoneme mapping tests the ability to make correct associations between letters or letter combinations and sounds in nonsense words. For example, children had to judge if oa in ploat stands for the same sound as ow in crow, or if $k n$ in knop stands for the same sound as the $k$ in kack. In morpheme mapping, children were presented with two words, and they had to decide if the first word came from the second word. Examples of this task are: builder and build (the answer is yes) and corner and corn (the answer is no).

\section{Results of the Study}

The language skills of all 10 dyslexic children improved at the end of the 3-week treatment. The researchers found that the two language tasks, phoneme mapping and morpheme mapping, lead to activation of different brain areas in both dyslexic children and normal readers. This suggests that the two language tasks require activity of different parts of the brain. When compared with normal readers, the amount of activation in dyslexic children in these areas was less before they received the reading treatment. The most important finding was that the activation patterns after the reading treatment increased in dyslexic children and were no different from normal readers.

\section{Summary}

The instructional treatment in dyslexic children resulted in improvement both in reading skills and brain activation patterns. The findings from this study suggest that reading treatment in children with dyslexia can be successful. When it is successful, the pattern of brain activity becomes similar to the activity pattern of normal readers of the same age. 


\section{What Is Dyslexia?}

'Dys' means 'difficulty' and 'lexia' means 'words'. Dyslexia is a disorder that affects millions of people all over the world. It is one type of specific learning disability that affects a person's ability to read. More specifically, people with dyslexia have difficulty with understanding language sounds, recognizing the meaning of words, and accurate spelling.

Studies show that people with dyslexia process language information in a different area of the brain than people without dyslexia. We believe that this is what leads to the language problems dyslexic people have. Despite this, most people with dyslexia have normal to above average intelligence. Even though they have a language problem, dyslexic people usually excel in one or more other areas, such as music, mathematics, or sports. A dyslexic person learns best when they can work at their own level and pace. There are many famous people with dyslexia, including the first president of the United States, George Washington, and Albert Einstein.

Low self-esteem is a common problem among dyslexic people. They may be considered to be lazy, unmotivated, or of low intelligence because of their language problem. These misconceptions can lead to many problems such as discouragement, isolation, feelings of inferiority, and low self-esteem.

\section{How Common Are Language- Based Learning Disabilities?}

About 15 to $20 \%$ of the population has a language-based learning disability. Of the students with learning disabilities who receive special education services at school, 70 to $80 \%$ have problems with reading. This makes dyslexia the most common learning disability. Dyslexia affects boys and girls nearly equally. It is seen in people from all ethnic groups and socio-economic levels as well.

\section{How Do People Get Dyslexia?}

Individuals inherit the tendency to develop dyslexia. That is, dyslexia runs in families. Chances are that one of the child's parents, grandparents, aunts, or uncles is dyslexic.

\section{Can Individuals Who Are Dyslexic Learn to Read?}

If children who are dyslexic get the proper instruction in kindergarten and 1st grade, they will have significantly fewer problems in learning to read at grade level than will children who are not identified or helped until 3rd grade. Unfortunately, many children are not recognized to have dyslexia this early on. About $74 \%$ of the children with dyslexia who are poor readers in 3 rd grade remain poor readers in the 9th grade. Often they can't read well as adults either. The earlier dyslexia is recognized and proper instruction given the better. However, it is never too late for individuals with dyslexia to learn to read and use other language skills better.

Special techniques are used to help dyslexic people learn to read. Dyslexic people are visual, multi-dimensional thinkers who are intuitive, highly creative, and excel at hands-on learning. A number of educational tools have been developed to teach people with dyslexia to read using pictures and computers. Every person with dyslexia is different. It is important that the dyslexic person's individual strengths and weaknesses be assessed to find the program that will help best.

\section{How Do I Know if a Person Is Dyslexic?}

Common signs of dyslexia vary depending on the person's age. Below is a list of the common signs of dyslexia in children in kindergarten through 4th grade. If some of these are present and are not consistent with the child's age and intellectual abilities, a trained professional should test him or her for dyslexia.

- May be slow to learn the connection between letters and sounds.

- Has difficulty decoding single words (reading single words in isolation).

- Has difficulty spelling phonetically.

- Makes consistent reading and spelling errors such as letter and word reversals.

- May confuse small words: "at" for "to," "said" for "and," "does" for "goes."

- Relies on guessing and context.

- May have difficulty learning new vocabulary.

- May transpose number sequences and confuse arithmetic signs (+ $\mathrm{x} / \mathrm{=}$ ).

- May have trouble remembering facts.

- May be slow to learn new skills; relies heavily on memorizing without understanding.

- May have difficulty planning, organizing, and managing time, materials, and tasks.

- Often uses an awkward pencil grip (fist, thumb hooked over fingers, etc.).

- May have poor "fine motor" coordination.

\section{For More Information:}

- National Institute of Child Health and Human Development, NIH, Bethesda, MD. www.nichd.nih.gov

- International Dyslexia Association. www.interdys.org 


\section{Neurology}

Reading treatment helps children with dyslexia and changes activity in language areas
of the brain

Shalini Narayana and Jinhu Xiong

Neurology 2003;61;E5-E6

DOI 10.1212/01.WNL.0000078769.20679.0E

This information is current as of July 21, 2003

Updated Information \&

Services

Permissions \& Licensing

Reprints including high resolution figures, can be found at:

http://n.neurology.org/content/61/2/E5.full

Information about reproducing this article in parts (figures,tables) or in its entirety can be found online at:

http://www.neurology.org/about/about_the_journal\#permissions

Information about ordering reprints can be found online:

http://n.neurology.org/subscribers/advertise

Neurology $®$ is the official journal of the American Academy of Neurology. Published continuously since 1951, it is now a weekly with 48 issues per year. Copyright . All rights reserved. Print ISSN: 0028-3878. Online ISSN: 1526-632X.

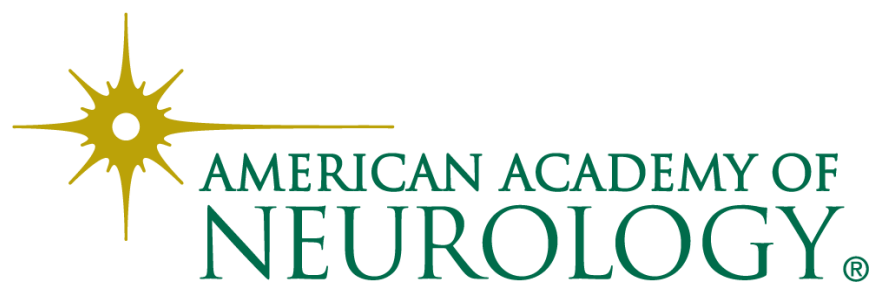

